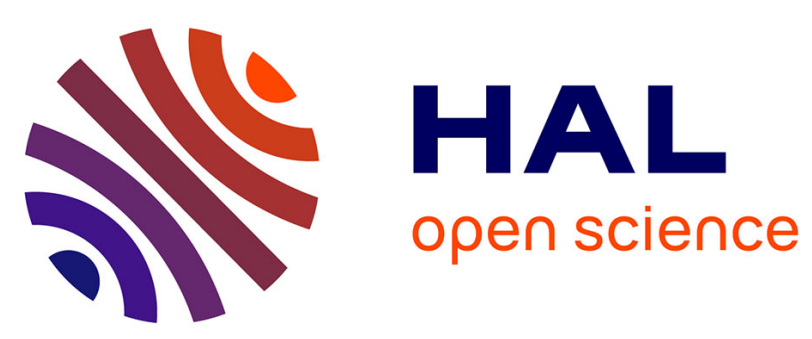

\title{
Size of submicrometric and nanometric particles affect cellular uptake and biological activity of macrophages in vitro
}

Lara Leclerc, Wael Rima, Delphine Boudard, Jérémie Pourchez, Valérie Forest, Valérie Bin, Pierre Mowat, Pascal Perriat, Olivier Tillement, Philippe Grosseau, et al.

\section{To cite this version:}

Lara Leclerc, Wael Rima, Delphine Boudard, Jérémie Pourchez, Valérie Forest, et al.. Size of submicrometric and nanometric particles affect cellular uptake and biological activity of macrophages in vitro. Inhalation Toxicology, 2012, 24 (9), pp.580-588. 10.3109/08958378.2012.699984 . hal-00733900

\section{HAL Id: hal-00733900 https://hal.science/hal-00733900}

Submitted on 20 Sep 2012

HAL is a multi-disciplinary open access archive for the deposit and dissemination of scientific research documents, whether they are published or not. The documents may come from teaching and research institutions in France or abroad, or from public or private research centers.
L'archive ouverte pluridisciplinaire HAL, est destinée au dépôt et à la diffusion de documents scientifiques de niveau recherche, publiés ou non, émanant des établissements d'enseignement et de recherche français ou étrangers, des laboratoires publics ou privés. 


\section{$\underline{\text { TITLE PAGE }}$}

Complete title:

Size of submicrometric and nanometric particles affect cellular uptake and biological activity of macrophages in vitro

Name and affiliation of each author:

L. LECLERC ${ }^{1,2,3}$, W. RIMA ${ }^{4}$, D. BOUDARD ${ }^{1,5,6}$, J. POURCHEZ ${ }^{1,2}$, V. FOREST ${ }^{1,2}$, V. BIN $^{1,5}$, P. MOWAT ${ }^{7}$, P. PERRIAT ${ }^{4}$, O. TILLEMENT ${ }^{7}$, P. GROSSEAU ${ }^{2}$, D. BERNACHE-ASSOLLANT ${ }^{1,2,3}$, M. COTTIER ${ }^{1,5,6}$.

${ }^{1}$ LINA, Laboratoire Interdisciplinaire d'étude des Nanoparticules Aérosolisées, EA 4624, F42023, Saint-Etienne, France

${ }^{2}$ Ecole Nationale Supérieure des Mines de Saint-Etienne, Centre Ingénierie et Santé, F-42023, Saint-Etienne, France

${ }^{3}$ Ecole Nationale Supérieure des Mines de Saint-Etienne, LPMG, FRE 3312 CNRS, F-42023, Saint-Etienne, France

${ }^{4}$ MATEIS, Université de Lyon, INSA-Lyon, F-69621, Villeurbanne, France.

${ }^{5}$ Université de Saint-Etienne, Jean Monnet, Faculté de Médecine, F-42023, Saint-Etienne, France

${ }^{6} \mathrm{CHU}$ de Saint-Etienne, Laboratoire d'Histologie, F-42055, Saint-Etienne, France

${ }^{7}$ LPCML, UMR 5620 CNRS, Université de Lyon, Université Claude Bernard, F-69622, Villeurbanne, France

Running headline: Nanoparticles size effect

Complete contact information:

Lara LECLERC

Centre Ingénierie et Santé

École Nationale Supérieure des Mines de Saint-Etienne

158, Cours Fauriel - 42023 Saint-Etienne Cedex 2, France

LINA - EA 4624

E-mail : leclerc@emse.fr

Tel: (+33) 477421425 Fax: (+33) 477421489 


\section{$\underline{\text { ABSTRACT AND KEY TERMS }}$}

Background: Micrometric and nanometric particles are increasingly used in different fields and may exhibit variable toxicity levels depending on their physicochemical characteristics. The aim of this study was to determine the impact of the size parameter on cellular uptake and biological activity, working with well-characterized fluorescent particles. We focused our attention on macrophages, the main target cells of the respiratory system responsible for the phagocytosis of the particles.

Methods: FITC fluorescent silica particles of variable submicronic sizes (850, 500, 250 and $150 \mathrm{~nm})$ but with similar surface coating $(\mathrm{COOH})$ were tailored and physico-chemically characterized. These particles were then incubated with the RAW 264.7 macrophage cell line. After microscopic observations (SEM, TEM, confocal), a quantitative evaluation of the uptake was carried out. Fluorescence detected after a quenching with trypan blue allows us to distinguish and quantify entirely engulfed fluorescent particles from those just adhering to the cell membrane. Finally, these data were compared to the in vitro toxicity assessed in terms of cell damage, inflammation and oxidative stress (evaluated by LDH release, TNF- $\alpha$ and ROS production respectively).

\section{Results and conclusion:}

Particles were well characterized (fluorescence, size distribution, zeta potential, agglomeration and surface groups) and easily visualized after cellular uptake using confocal and electron microscopy. The number of internalized particles was precisely evaluated. Size was found to be an important parameter regarding particles uptake and in vitro toxicity but this latter strongly depends on the particles doses employed.

Key terms: Uptake quantification, macrophages, fluorescent particles, in vitro toxicity. 


\section{$\underline{\text { INTRODUCTION }}$}

The toxicological assessment of fine and ultrafine particles (and particularly engineered nanoparticles) currently represents a considerable issue for environmental science, biosciences or nanomedicine (Warheit, 2004; Oberdorster, 2005; Sayes, 2007). In order to improve our knowledge of the biological toxicity and the uptake mechanisms of submicronic particles, it seems of high interest to propose a quantitative assessment of the number of internalized particles into the cells after exposure (Haberzettl, 2007; Clift, 2008). Different particle entry pathways exist in the organism: skin, gastro-intestinal tract, respiratory tract or by injection. We focus our attention especially on the respiratory way and its main target cells: the macrophages. They are the main actors of phagocytosis, a highly conserved complex process, classically defined as the internalization and destruction of particles greater than 0.5 $\mu \mathrm{m}$ in size. Phagocytosis is a receptor-mediated and actin-driven process. It involves actin dynamics including polymerization, bundling, contraction, severing and depolymerization of actin filaments (Aderem, 1999; Fenteany, 2004; Niedergang, 2004, 2005; Ravetch, 2007).

Slight physicochemical differences in the particles surface may influence the phagocytic process (Serda, 2009) and they have also been shown to be involved in toxicological processes (Fubini, 1998; Fubini, 2004; Clift, 2008). It appears of great concern to us to establish the relationship between the quantification of the uptake and the biotoxicity of the particles depending on their physicochemical features (size, surface reactivity, etc.).

Different studies have investigated the impact of nanoparticles size on uptake but with various types of particles without fully characterized physico-chemical parameters or agglomeration state (Rejman, 2004). Moreover, little attention has been paid to an accurate quantification process frequently reduced to a simple quantification of fluorescence $(\mathrm{Hu}$, 2007; Su, 2010; Yan, 2010). In most cases, only the parameter of mean fluorescence intensity has been taken into account. Sometimes uptake is just visualized with microscopy techniques 
and not quantified at all (Song, 2010). Therefore, the study of particles uptake generally remains qualitative or semi-quantitative.

In this paper, we focused our attention on the impact of particles size on their uptake and toxicity. First, we synthesized silica fluorescent particles with well controlled features (size, surface groups, fluorescence, shape, zeta potential, etc.) of four different sizes $(150,250,500$ and $850 \mathrm{~nm}$ ). The physicochemical features of these particles were validated in cell free conditions using various techniques: Dynamic Light Scattering (DLS), confocal microscopy, Scanning Electron Microscopy (SEM), Transmission Electron Microscopy (TEM) and zeta potential measurements.

Then the particles were incubated with a macrophage cell line (RAW 264.7) and their uptake and subcellular localization were observed using confocal microscopy and TEM. However, these techniques did not allow for an accurate quantification of the phagocytic process. To propose a quantitative assessment of the number of internalized particles, we used the trypan blue (TB) quenching method in fluorimetry. In addition to its principal function as an exclusion dye of dead cells, TB is known for its ability to "turn off" the green fluorescence emitted by the particles outside the cells. This process allowed us to distinguish internalized particles from those just adhering to the plasma membrane (Hed, 1987; Van Amersfoort, 1994; Thiele, 2001; Nuutila, 2005). Moreover, the toxicity of particles was evaluated regarding several complementary parameters: Tumor Necrosis Factor alpha (TNF- $\alpha$ ) production (to assess the inflammatory response), Lactate Dehydrogenase (LDH) release (reflecting the integrity of the cell membrane) and the production of different Reactive Oxygen Species (ROS) (Catelas, 1999; Donaldson, 2002; Bruch, 2004; Sayes, 2007). This part aimed at assessing if the size of the particles had a major impact on the level of toxicity. Thus, the present work exposed an appropriate and precise methodology to investigate the relationship between the particles size, their level of uptake and the induced toxicity. 


\section{$\underline{\text { MATERIAL AND METHODS }}$}

\section{Fluorescent silica-based particles}

\section{Synthesis}

Four types of fluorescent silica-based particles with variable and well-controlled sizes (150, 250, 500 and $850 \mathrm{~nm}$ ) were synthesized at the laboratory scale (Nano-H, France). The particles were constituted of silica core doped with Fluoresceine isothiocyanate Isomere I $\left(\mathrm{C}_{21} \mathrm{H}_{11} \mathrm{NO}_{5} \mathrm{~S}\right.$, FITC, $\geq 90 \%$, Sigma-Aldrich) exhibiting a green fluorescence and grafted by covently bonds, as described by Van Blaaderen et al. and Wang et al. (Van Blaaderen, 1992; Wang, 2003). Then a controlled polysiloxane shell ( $\mathrm{SiOx})$ was introduced, by hydrolysis condensation of 3-aminopropyl triethoxysilane $\left(\mathrm{H}_{2} \mathrm{~N}\left(\mathrm{CH}_{2}\right)_{3}-\mathrm{Si}\left(\mathrm{OC}_{2} \mathrm{H}_{5}\right)_{3}\right.$, APTES, 99\%, Sigma-Aldrich) and tetraethyl orthosilicate $\left(\mathrm{Si}\left(\mathrm{OC}_{2} \mathrm{H}_{5}\right)_{4}, \mathrm{TEOS}, \geq 99 \%\right.$, Sigma-Aldrich) using alcohol as solvent in presence of catalytic agent. Finally the particles were stabilized by introducing carboxylic surface groups $(\mathrm{COOH})$ onto the surface using diethylenetriamine pentaacetic dianhydride DTPA-ba (TCI Europe) as reagent. The synthesis was performed as follows: a solution of DTPA-ba was stirred and added to the colloid solution containing nanoparticles at room temperature. Then the final solution was purified by centrifugation and redispersed in ethanol. The particles were then redispersed in water at a desired concentration (particles number/mL).

Particles fluorescence $\left(\% \mathrm{~m} / \mathrm{mSiO}_{2}\right)$ was fixed at $3 \%$. Excitation and emission wavelengths of the FITC were $488 \mathrm{~nm}$ and $495-550 \mathrm{~nm}$ respectively.

\section{Characterization}

Dynamic light scattering (DLS) and zeta potential measurement

Measurement of the size distribution of the different submicronic particles and their zeta potential were performed using a Zetasizer Nano S from Malvern instrument (Orsay, France) 
in water and in complete culture media (DMEMc, precisely defined in the macrophage cell culture section) after strong vortexing $(n=3)$. Particles agglomeration was also followed in complete culture media after 8 and 24 hours.

\section{$\underline{\text { Transmission electron microscopy }}$}

Transmission electron microscope (TEM) images were obtained using a JEOL 2010F FEG microscope at a $200 \mathrm{kV}$ accelerating voltage. Samples were prepared by dropping sample suspension on a carbon-coated holey film supported on a $3 \mathrm{~mm}$ mesh copper grid. Particles mean size was evaluated using "Precipite" Software (@ T. Epicier 2005).

$\underline{\text { Scanning electron microscopy }}$

Scanning electron microscopy (SEM) images of particles were performed using an ESEM XL30-FEI microscope equipped with a thermal field emission gun (FEG).

\section{$\underline{\text { Fluorescence spectral analysis }}$}

Spectral measurements of particles suspensions were acquired with an excitation wavelength of $490 \mathrm{~nm}$ and emission fluorescence spectral curves were collected over the 490-800 nm wavelength range (Fluorescence spectrophotometer F-2500, Hitachi).

\section{Cellular assays}

Macrophage cell culture and dose of particles

The RAW 264.7 cell line was provided by ATCC Cell Biology Collection (Promochem LGC, Molsheim, France) and derives from mice peritoneal macrophages transformed by the AMLV (Abelson Murine Leukemia Virus). Cells were cultured in Dulbecco's Modified Eagle's Medium (DMEM, Invitrogen), complemented with 10\% of fetal calf serum (FCS, Invitrogen), $1 \%$ penicillin-streptomycin (penicillin 10000 units $/ \mathrm{mL}$, streptomycin $10 \mathrm{mg} / \mathrm{mL}$; SigmaAldrich, Saint-Quentin Fallavier, France) and incubated at $37^{\circ} \mathrm{C}$ under a 5\% carbon dioxide humidified atmosphere. 
For each experiment, an arbitrary ratio of 1000 particles for one cell was used and incubated 24 hours with macrophages.

\section{Confocal imaging}

Cells were grown in 6 well plates $(1$ million cells/well in $4 \mathrm{~mL})$ containing coverslips. After a 24 hour exposure to particles, the coverslips were fixed into the wells with $4 \%$ paraformaldehyde (PFA) for 10 minutes. The wells were washed with Phosphate Buffered Saline (PBS, VWR, Fontenay-sous-Bois, France) to remove excess particles that did not adhere to cell membrane or were not internalized. Then, actin cytoskeleton was labeled with AlexaFluor® 594 phalloidin (Invitogen; diluted 1:40 in PBS) for 20 min and rinsed with PBS. Finally cell nuclei were stained with $10 \mu \mathrm{M}$ of Hoechst 33342 solution (Sigma), during 15 minutes and rinsed with PBS. Coverslips were then sticked to microscope slide using Vectashield HardSet Mounting Medium (Vector, Cliniscience, Montrouge, France).

Analyses were performed using a confocal microscope TCS-SP2 from Leica Microsystems (Leica®, Heidelberg, Germany). Images were obtained from the fluorescence emitted by FITC (ex: $488 \mathrm{~nm}$; em: 495-550 nm), AlexaFluor®594 phalloidin (ex: $581 \mathrm{~nm}$; em: $609 \mathrm{~nm}$ ) and Hoechst (ex: $355 \mathrm{~nm}$; em: $465 \mathrm{~nm}$ ).

\section{Transmission Electron Microscopy (TEM)}

Cells were grown in 6 well plates ( 1 million cells/well in $4 \mathrm{~mL})$ containing coverslips and particles were incubated for 24 hours. After washing to remove unfixed or non-internalized particles, cells on coverslips were fixed with a solution of $2 \%$ glutaraldehyde / $0.1 \mathrm{M}$ Cacodylate at $\mathrm{pH} 7.4$, washed three times in $0.1 \mathrm{M}$ sodium cacodylate buffer and postfixed in $1 \%$ osmium tetroxide. After washing, samples were dehydrated by graded series of ethanol 
baths, embedded in Epon and finally cut by ultramicrotomy. Observations were carried out on the 70nm thick samples using a Hitachi $\mathrm{H}-800$ electron microscope operating at $200 \mathrm{kV}$.

\section{Quantitative uptake assessment}

Cells were grown in 96 well plates (100 000 cells per well in $200 \mu \mathrm{L}$ of complete culture medium). Medium was replaced by $200 \mu \mathrm{L}$ of diluted particles (ratio of 1000 particles/cell) in the test wells. Fluorescence intensity standard curves were simultaneously established for each size of particles and fluorescence was detected using a fluorometer (Fluoroskan Ascent, Thermolabsystems), with 485/538 nm excitation/emission wavelengths.

Measures of fluorescence were performed immediately after particles addition and after 24 hours of incubation $\left(37^{\circ} \mathrm{C}, 5 \% \mathrm{CO}_{2}\right)$ with washing steps and use of trypan blue (TB) (diluted 1:2) for half of the media test wells. Using the standard curves established for each size of particles and as TB is known to quench the fluorescence of particles that are not internalized, this technique allowed to determine precisely the number of particles in contact with cells (internalized and adhering to cell membrane and, by difference, the precise number of internalized particles). Results are expressed as percentage of particles initially introduced remaining in the supernatant, particles adhering to cell membranes and intracellular particles.

\section{Toxicity assessment}

For each experiment, cells were prepared in 96-well plates (100 000 cells/well for TNF- $\alpha$ and LDH assays, and 300000 cells/well for ROS and $\mathrm{H}_{2} \mathrm{O}_{2}$ parameters) in $25 \mu \mathrm{L}$ of complete DMEM. Particles (1000/cell in a volume of $75 \mu \mathrm{L}$ of DMEM) were added to the culture and incubated for $24 \mathrm{~h}$ at $37^{\circ} \mathrm{C}$. In each case, control cells were incubated in the same conditions but without particles. 
TNF- $\alpha$ production (Quantikine ${ }^{\circledR}$ Mouse TNF- $\alpha$ Immunoassay, R\&D Systems), LDH release (CytoTox-ONETM Homogeneous Membrane Integrity Assay, Promega), oxidative stress (OxiSelect ${ }^{\mathrm{TM}}$ ROS Assay Kit, Euromedex) and specific Hydrogen Peroxide $\left(\mathrm{H}_{2} \mathrm{O}_{2}\right)$ in shortterm (90 min) and long-term (24h) conditions (De la Harpe, 1985) were analyzed as extensively described in a previous work (Leclerc, 2010).

\section{Statistical analysis}

Analysis and graphics were performed on Prism 5.0 software (GraphPad, San Diego, CA). Significance $(* * *)$ was established with ANOVA test $(\mathrm{p}<0.05)$. 


\section{$\underline{\text { RESULTS }}$}

\section{Physicochemical characterizations}

The physicochemical properties of the particles are summarized in Table 1. All particles contain the same massic percentage of FITC and the same type of surface groups $(\mathrm{COOH})$. This table also shows the silicon concentration of each particle and the number of $\mathrm{COOH}$ groups per particle. Physicochemical characterizations in terms of size and zeta potential are compared in Table 2 for particles resuspended either in water or in complete culture media. There is a good correlation between the expected sizes of particles and those measured using DLS and TEM, except for the $150 \mathrm{~nm}$ particles that appear bigger in DLS due to agglomeration process. There are slight differences between sizes evaluated by DLS in water or in complete culture media with a noticeable increase in the culture medium. This could be due to the adsorption of some culture media proteins onto particles surface.

Colloidal particles dispersed in a solution are electrically charged due to their ionic characteristics and dipolar attributes. Zeta potential is considered to be the electric potential of the particles. As this electric potential approaches zero, particles tend to aggregate. Zeta potential values always appear negative, but are clearly higher ( 2 fold) in culture media than in water. This phenomenon may also be due to the adsorption of proteins contained in the culture medium on the particles or to the charge screening generally observed in highly ionized solutions (but further investigations are needed to confirm this hypothesis). Also, the protein corona may inhibit particles surface charge. However these results indicate that the particles are well-dispersed.

Uniformity of particle size and shape was verified using SEM and TEM (Figure 1). Particles appeared spherical, non-agglomerated with well-defined size ranges. Moreover, concerning the agglomeration state, particles size distribution was assessed in complete culture media over time (0, 8 and 24h) as shown on Figure 2. Results indicate that the different sizes of 
particles present a remarkable size stability, avoiding agglomeration phenomena even in culture media containing serum.

The fluorescence spectrum of the FITC was also checked for each particles size (Figure 3). A specific fluorescence intensity (arbitrary units) was observed for each type of particles due to the percentage in mass of FITC employed in the particles' synthesis. These variations are normal but important to consider in the rest of the study especially for the fluorescence quantification with the fluorometer. In this case, standard curves for each particle size have to be established.

\section{Qualitative uptake assessment by microscopy}

After cellular contacts, particles were imaged using confocal microscopy. As shown on Figure 4, particles of the four sizes were detectable (FITC green labeling). $150 \mathrm{~nm}$ particles were less visible but it could be explained by the detection threshold of the microscope (200 nm resolution). However, confocal observations allowed us to distinguish particles localization using stacks sections. In each case, particles were surrounded by the actin cytoskeleton (Phalloidin red labeling) validating their internalization by macrophages. Indeed, F-actin, the major component of cells cytoskeleton, is associated with the phalloidin which labeling allows precise visualization of actin cortex under the cell membrane.

TEM acquisitions were then performed to detect more accurately particles localization in the intracellular compartment (Figure 5). Electron micrographs obtained using an electron beam at $200 \mathrm{kV}$ show that, after incubation at a concentration of 1000 particles/cell, particles are gathered in the cells' vesicles separated from the cytoplasm by a double membrane. Moreover TEM images indicate that particles could be internalized individually or by groups (two, three or more). Micrographs also give some indication about the mechanism of internalization. 
Adhesion steps have been visualized in SEM and showed particles absorbed on the cell membrane (data not shown).

\section{Quantitative uptake assessment by fluorometry}

Results of the Fluoroskan quantification of uptake are presented on Figure 6 where the amount of particles (expressed as a percentage of particles initially introduced) is reported as a function of their localization: either at the membrane surface, in the intracellular space or remaining in the culture supernatant. The measurement of the total fluorescence of FITC allows us to determine the number of particles internalized and adhering to the cell membranes. Then the accurate quantification of the amount of particles entirely engulfed in the cells was made possible by the use of TB which is known to quench the fluorescence of the particles remaining outside the cells. Finally, the amount of particles that remained in the supernatant was determined by deduction (total number of particles - amount of particles adhering to membranes and internalized - amount of particles entirely internalized within cells).

The 850,500 and $250 \mathrm{~nm}$ particles are internalized at the same rate, respectively $17 \%, 14 \%$ and $12 \%$ with a very low percentage of adherent particles ( $2 \%$ or $4 \%)$. On the contrary, the smallest ones appeared much more internalized (24\%) with a non negligible $10 \%$ of adherence.

This methodology allows us also to determine the number of particles internalized per cell (e.g.: $148 \pm 5$ for the $500 \mathrm{~nm}$ particles and $265 \pm 32$ for the $150 \mathrm{~nm}$ particles).

\section{Toxicity assessment}

Concerning toxicity assessment, results are presented on Figure 7. The dose employed was fixed at 1000 particles per cell. Results showed a size dependent effect from the smallest to 
the biggest particles sizes especially for the parameters of TNF- $\alpha$ reflecting inflammation and LDH representative of membranes alterations (Figure $7 \mathrm{~A}$ and $\mathrm{B}$ ). The $\mathrm{H}_{2} \mathrm{O}_{2}$ production was also assessed for specific short-term and long-term conditions (Figure $7 \mathrm{C}$ and D) and finally total ROS production was quantified (Figure $7 \mathrm{E}$ ). Effects were not significant regarding total and short-term $\mathrm{H}_{2} \mathrm{O}_{2}$ but a slight increase (nmol) was noticed for long-term $\mathrm{H}_{2} \mathrm{O}_{2}$ for the biggest particles.

The $850 \mathrm{~nm}$ particles appear biologically more active than the others at the dose employed in this study. 


\section{DISCUSSION}

This study aimed at understanding the relationship between particles' physicochemical features (especially the size), their uptake and toxicity. Fluorescent particles of various submicronic sizes $(850,500,250$ and $150 \mathrm{~nm}$ ) but exhibiting the same surface coating $(\mathrm{COOH})$ were characterized for sizes and zeta potential by DLS, TEM and their fluorescent spectra were also measured for calibration. Size distributions evaluated by DLS were in agreement with those measured in TEM. Moreover, concerning agglomeration phenomena, no noticeable difference was observed between analyses in water and in complete culture media, the high size stability over time due to the $\mathrm{COOH}$ surface functionalization being due to the strong negatives values of zeta potential.

First, the fluorescent particles were well-defined in terms of physicochemical characteristics and were well-dispersed, which is a mandatory step for further toxicological evaluations (Ahsan, 2002; Fubini, 2010; Warheit, 2010). Once characterized, the particles were incubated with macrophages and uptake was qualitatively and quantitatively assessed before the evaluation of the biological activity parameters.

Even if microscopy visualization confirms the efficiency of particles' uptake with a precise localization throughout cells, quantification could not be done precisely and statistically on images (Clift, 2008; Song, 2010). Another technique allowing us to quantify the physical process of internalization is needed. Moreover, it is also important to take into account the proportion of particles adhering to cell membrane (Gratton, 2008). This is the reason why we have developed quantitative approaches for particles uptake with fluorescent detection using a fluorometer with a trypan blue quenching to distinguish entirely engulfed fluorescent particles from those that just adhered to the cell membrane (Leclerc, 2010).

Results indicate that fluorometer analyses are sensitive enough to permit precise uptake quantification. Trypan blue allowed for the distinction between the internalized and adherent 
particles and their respective amounts to be expressed as a percentage. Fluorescent quantification indicates that $150 \mathrm{~nm}$ particles (the smallest ones) appear more internalized than the others $(24 \%)$. The native size of these particles is around $70 \mathrm{~nm}$ and it is the size of the agglomerate that reaches $150 \mathrm{~nm}$. For the other sizes, the amount of internalized particles slowly decreases with decreasing size. Taken together the results indicate that the agglomerate morphology may enhance the phagocytosis. This can be due to a charge distribution within the agglomerate that could modify the cell/particle interaction and/or to its significantly lower density (volumic mass) that could favour, for mechanical reasons, its entry through the membrane. It would be interesting in further study to compare the internalization rate of two objects of same size: a bulk one consisting of only one particle and another one consisting of an agglomerate of smaller particles with the aim to observe a difference in the rate or the pathway of internalization. Moreover results should be compared to smaller sizes of particles (at the nanoscale).

Another important aspect visualized on TEM images is that many particles can be internalized in a same vesicle or otherwise can be free in the cytoplasm. For the particle sizes used in this study, phagocytosis is generally the specific pathway employed by phagocytic cells such as macrophages but other internalization pathways could be involved (Aderem, 1999; Castellano, 2001; Etienne-Manneville, 2002; Niedergang, 2004, 2005; Haberzettl, 2007; Lanzetti, 2007; Yeung, 2007; Gratton, 2008). It would be interesting to explore pathways such as energy-dependent phagocytosis, clathrin-mediated endocytosis, caveolae-mediated endocytosis, or macropinocytosis in a further study.

Finally, these quantitative data were correlated to in vitro toxicity assessments (TNF- $\alpha$ and LDH release, ROS production). Indeed, toxicity evaluations reported in the literature showed that the doses employed are very important in result interpretation (Oberdorster, 2005; Fubini, 
2010). In this study we worked with an equivalent number of particles regardless of the sizes, a metric currently used in uptake studies (Champion, 2008). At this dose, the biggest particles $(850 \mathrm{~nm})$ appeared more biologically reactive (higher values $e . g$. for TNF- $\alpha$ as compared to control cells) with a significant size effect. Reproducing analysis with the same volume or the same surface of particles for the different sizes at different doses will be interesting.

This work shows no direct correlation between the number of internalized particles and the biological data of toxicity. Indeed, $150 \mathrm{~nm}$ particles are more internalized but their biological effects are not significant for the different parameters evaluated. When working at the 1000 particles/1 cell ratio, the biggest particles $(850 \mathrm{~nm})$ are more toxicologically reactive.

This suggests that the inhalation of larger sized particles is pro-inflammatory for macrophages of the alveolar spaces and strongly encouraged the development of nanosized particles for drug delivery systems or diagnosis. Although macrophages are related to other cell types in vivo such as pneumocytes which are not taken into account in this in vitro study, they remain the major players of the inflammatory response and give us an idea of the biological response to different sizes of particles.

\section{Conclusion}

The aim of this study was to analyze the effect of the size of particles on their uptake and the induced toxicity. To that purpose, we coupled imaging analysis, quantification techniques and biological evaluations. This approach confirms that particle size represents a key physicochemical characteristic which has an important impact on uptake but is not directly related to biological activity. It will be interesting to investigate other parameters such as surface charge of particles (Lundqvist et al., 2008). 


\section{ACKNOWLEDGEMENTS}

We would like to acknowledge the help and support of our collaborators. We are grateful to Nano-H Company for providing the nanoparticles. We also acknowledge the excellent assistance of CT $\mu$ (Centre Technique des Microstructures) for cells samples preparation for TEM, CLYM (Centre Lyonnais de Microscopie) and CMES (Centre de Microscopie Electronique Stéphanois) for the access to the different electron microscopes. We are also grateful to Centre de Quantimétrie Cellulaire for the confocal images.

The authors would like to acknowledge the financial support of the Conseil Général de la Loire.

\section{DECLARATION OF INTEREST}

The authors report no declarations of interest.

\section{$\underline{\text { REFERENCES }}$}

Aderem A, Underhill DM. 1999. Mechanisms of phagocytosis in macrophages. Annu Rev Immunol 17:593-623.

Ahsan F, Rivas IP, Khan MA, Torres Suarez AI. 2002. Targeting to macrophages: role of physicochemical properties of particulate carriers--liposomes and microspheres--on the phagocytosis by macrophages. J Control Release 79:29-40.

Bruch J, Rehn S, Rehn B, Borm PJ, Fubini B. 2004. Variation of biological responses to different respirable quartz flours determined by a vector model. Int J Hyg Environ Health 207:203-216.

Castellano F, Chavrier P, Caron E. 2001. Actin dynamics during phagocytosis. Semin Immunol 13:347-355. 
Catelas I, Petit A, Marchand R, Zukor DJ, Yahia L, Huk OL. 1999. Cytotoxicity and macrophage cytokine release induced by ceramic and polyethylene particles in vitro. $\mathrm{J}$ Bone Joint Surg Br 81:516-521.

Champion JA, Walker A, Mitragotri S. 2008. Role of Particle Size in Phagocytosis of Polymeric Microspheres. Pharm Res.

Clift MJ, Rothen-Rutishauser B, Brown DM, Duffin R, Donaldson K, Proudfoot L, Guy K, Stone V. 2008. The impact of different nanoparticle surface chemistry and size on uptake and toxicity in a murine macrophage cell line. Toxicol Appl Pharmacol 232:418-427.

De la Harpe J, Nathan CF. 1985. A semi-automated micro-assay for $\mathrm{H} 2 \mathrm{O} 2$ release by human blood monocytes and mouse peritoneal macrophages. J Immunol Methods 78:323336.

Donaldson K, Brown D, Clouter A, Duffin R, MacNee W, Renwick L, Tran L, Stone V. 2002. The pulmonary toxicology of ultrafine particles. J Aerosol Med 15:213-220.

Etienne-Manneville S, Hall A. 2002. Rho GTPases in cell biology. Nature 420:629-635.

Fenteany G, Glogauer M. 2004. Cytoskeletal remodeling in leukocyte function. Curr Opin Hematol 11:15-24.

Fubini B. 1998. Surface chemistry and quartz hazard. Ann Occup Hyg 42:521-530.

Fubini B, Fenoglio I, Ceschino R, Ghiazza M, Martra G, Tomatis M, Borm P, Schins R, Bruch J. 2004. Relationship between the state of the surface of four commercial quartz flours and their biological activity in vitro and in vivo. Int J Hyg Environ Health 207:89-104.

Fubini B, Ghiazza M, Fenoglio I. 2010. Physico-chemical features of engineered nanoparticles relevant to their toxicity. Nanotoxicology 4:347-363.

Gratton SE, Ropp PA, Pohlhaus PD, Luft JC, Madden VJ, Napier ME, DeSimone JM. 2008. The effect of particle design on cellular internalization pathways. Proc Natl Acad Sci U S A 105:11613-11618. 
Haberzettl P, Duffin R, Kramer U, Hohr D, Schins RP, Borm PJ, Albrecht C. 2007. Actin plays a crucial role in the phagocytosis and biological response to respirable quartz particles in macrophages. Arch Toxicol 81:459-470.

Hed J, Hallden G, Johansson SG, Larsson P. 1987. The use of fluorescence quenching in flow cytofluorometry to measure the attachment and ingestion phases in phagocytosis in peripheral blood without prior cell separation. J Immunol Methods 101:119-125.

Hu Y, Xie J, Tong YW, Wang CH. 2007. Effect of PEG conformation and particle size on the cellular uptake efficiency of nanoparticles with the HepG2 cells. J Control Release 118:717.

Lanzetti L. 2007. Actin in membrane trafficking. Curr Opin Cell Biol 19:453-458.

Leclerc L, Boudard D, Pourchez J, Forest V, Sabido O, Bin V, Palle S, Grosseau P, Bernache D, Cottier M. 2010. Quantification of microsized fluorescent particles phagocytosis to a better knowledge of toxicity mechanisms. Inhal Toxicol 22:1091-1100.

Lundqvist M, Stigler J, Elia G, Lynch I, Cedervall T, Dawson KA. 2008. Nanoparticle size and surface properties determine the protein corona with possible implications for biological impacts. Proc Natl Acad Sci U S A 105:14265-14270.

Niedergang F, Chavrier P. 2004. Signaling and membrane dynamics during phagocytosis: many roads lead to the phagos(R)ome. Curr Opin Cell Biol 16:422-428.

Niedergang F, Chavrier P. 2005. Regulation of phagocytosis by Rho GTPases. Curr Top Microbiol Immunol 291:43-60.

Nuutila J, Lilius EM. 2005. Flow cytometric quantitative determination of ingestion by phagocytes needs the distinguishing of overlapping populations of binding and ingesting cells. Cytometry A 65:93-102.

Oberdorster G, Oberdorster E, Oberdorster J. 2005. Nanotoxicology: an emerging discipline evolving from studies of ultrafine particles. Environ Health Perspect 113:823-839. 
Ravetch J, Aderem A. 2007. Phagocytic cells. Immunol Rev 219:5-7.

Rejman J, Oberle V, Zuhorn IS, Hoekstra D. 2004. Size-dependent internalization of particles via the pathways of clathrin- and caveolae-mediated endocytosis. Biochem $\mathbf{J}$ 377:159-169.

Sayes CM, Reed KL, Warheit DB. 2007. Assessing toxicity of fine and nanoparticles: comparing in vitro measurements to in vivo pulmonary toxicity profiles. Toxicol Sci 97:163180.

Serda RE, Gu J, Burks JK, Ferrari K, Ferrari C, Ferrari M. 2009. Quantitative mechanics of endothelial phagocytosis of silicon microparticles. Cytometry A 75:752-760.

Song MM, Song WJ, Bi H, Wang J, Wu WL, Sun J, Yu M. 2010. Cytotoxicity and cellular uptake of iron nanowires. Biomaterials 31:1509-1517.

Su Y, Xu JY, Shen P, Li J, Wang L, Li Q, Li W, Xu GT, Fan C, Huang Q. 2010. Cellular uptake and cytotoxic evaluation of fullerenol in different cell lines. Toxicology 269:155-159.

Thiele L, Rothen-Rutishauser B, Jilek S, Wunderli-Allenspach H, Merkle HP, Walter E. 2001. Evaluation of particle uptake in human blood monocyte-derived cells in vitro. Does phagocytosis activity of dendritic cells measure up with macrophages? J Control Release 76:59-71.

Van Amersfoort ES, Van Strijp JA. 1994. Evaluation of a flow cytometric fluorescence quenching assay of phagocytosis of sensitized sheep erythrocytes by polymorphonuclear leukocytes. Cytometry 17:294-301.

Van Blaaderen A, Vrij A. 1992. Synthesis and characterization of colloidal dispersions of fluorescent, monodisperse silica spheres. In: Langmuir. p 2921-2931.

Wang W, Gu B, Liang L, Hamilton W. 2003. Fabrication of Two- and Three-Dimensional Silica Nanocolloidal Particle Arrays. In: The Journal of Physical Chemistry B. p 3400-3404. 
Warheit DB. 2010. Debunking Some Misconceptions about Nanotoxicology. Nano Lett:4777-4782.

Warheit DB, Laurence BR, Reed KL, Roach DH, Reynolds GA, Webb TR. 2004. Comparative pulmonary toxicity assessment of single-wall carbon nanotubes in rats. Toxicol Sci 77:117-125.

Yan F, Zhang C, Zheng Y, Mei L, Tang L, Song C, Sun H, Huang L. 2010. The effect of poloxamer 188 on nanoparticle morphology, size, cancer cell uptake, and cytotoxicity. Nanomedicine 6:170-178.

Yeung T, Grinstein S. 2007. Lipid signaling and the modulation of surface charge during phagocytosis. Immunol Rev 219:17-36. 


\section{TABLES WITH CAPTIONS}

\begin{tabular}{|c|c|c|c|}
\hline $\begin{array}{c}\text { Expected size } \\
(\mathrm{nm})\end{array}$ & [Si] M & Wt \% FITC & $\begin{array}{c}\text { Number of COOH } \\
\text { groups / particle }\end{array}$ \\
\hline 150 & 2,7 & $3 \%$ & $1,89 \mathrm{E}+07$ \\
\hline 250 & 2,5 & $3 \%$ & $6,75 \mathrm{E}+07$ \\
\hline 500 & 1,65 & $3 \%$ & $2,62 \mathrm{E}+08$ \\
\hline 850 & 2,2 & $3 \%$ & $4,90 \mathrm{E}+08$ \\
\hline
\end{tabular}

Table 1: Characteristics of the four types of particles.

\begin{tabular}{|c|c|c|c|c|c|}
\cline { 3 - 6 } \multicolumn{2}{c|}{} & \multicolumn{2}{c|}{ Water } & \multicolumn{2}{c|}{ DMEMc } \\
\hline $\begin{array}{c}\text { Expected } \\
\text { size }(\mathrm{nm})\end{array}$ & $\begin{array}{c}\text { Mean size in } \\
\text { TEM }(\mathrm{nm})\end{array}$ & $\begin{array}{c}\text { Mean size by } \\
\text { DLS }(\mathrm{nm})\end{array}$ & $\begin{array}{c}\text { Zêta potential } \\
(\mathrm{mV})\end{array}$ & $\begin{array}{c}\text { Mean size by } \\
\text { DLS }(\mathrm{nm})\end{array}$ & $\begin{array}{c}\text { Zêta potential } \\
(\mathrm{mV})\end{array}$ \\
\hline 150 & $67 \pm 6$ & $139 \pm 2$ & $-54,2 \pm 0,9$ & $158 \pm 3$ & $-23,1 \pm 1,4$ \\
\hline 250 & $275 \pm 26$ & $252 \pm 4$ & $-54,5 \pm 0,9$ & $279 \pm 4$ & $-24,5 \pm 1,5$ \\
\hline 500 & $446 \pm 37$ & $492 \pm 6$ & $-65,6 \pm 0,3$ & $536 \pm 10$ & $-22,6 \pm 2,2$ \\
\hline 850 & $760 \pm 25$ & $847 \pm 19$ & $-68,7 \pm 0,1$ & $820 \pm 10$ & $-17,1 \pm 1,6$ \\
\hline
\end{tabular}

Table 2: Measurement of particles size and zeta potential. Particles mean size was evaluated on TEM images. Comparison were established between size distributions evaluated by DLS and zeta potential for particles diluted in water or in complete cellular culture medium (DMEMc). Data are expressed as means $\pm \mathrm{SE}(\mathrm{n}=3)$. 


\section{FIGURE CAPTIONS}

Figure 1: TEM (column A) and SEM (column B) imaging of the four types of particles in cell free conditions.

Figure 2: DLS evaluations of particles size in complete culture media (DMEMc) for different times of incubation $(0,8$ and $24 \mathrm{~h})$ in cell free conditions.

Figure 3: Fluorescence intensity evaluated in arbitrary units for each particle type. Spectral measurements were acquired with a $490 \mathrm{~nm}$ excitation wavelength and emission fluorescence spectral curves were collected over the $490-800 \mathrm{~nm}$ wavelength range. The four sizes of particles show a specific peak of FITC between 490 and $560 \mathrm{~nm}$.

Figure 4: Confocal microscopy images of macrophages incubated for 24 hours with FITC (green) particles (1000/1 cell) of different sizes (B-E). Control cells (A) were incubated without particles. Phalloidin (F-actin - Red) and Hoechst (cell nuclei - Blue) labelings allowed structures localizations.

Figure 5: Electron microscopy of particles after cellular contacts with RAW 264.7 macrophages for 24 hours. A) and B) $250 \mathrm{~nm}$ particles, C) and D) $500 \mathrm{~nm}$ particles. 
These images show particles internalized within the cells in the cytoplasm gathered in double membrane vacuoles. $500 \mathrm{~nm}$ particles seem internalized individually whereas several $250 \mathrm{~nm}$ particles are internalized in a same vesicle.

Figure 6: Particles uptake quantification using trypan blue quenching and Fluoroskan analysis. Results are expressed as percentage of particles per compartment: supernatant, adherent to cell membranes, intracellular. Standard curves in number of particles have been established for each size of particles. This figure presents one graphic per size: A) $850 \mathrm{~nm}$, B) $500 \mathrm{~nm}$, C) $250 \mathrm{~nm}$ and D) $150 \mathrm{~nm}$. Data represent for each particle size the mean and standard error of $\mathbf{n}=4$. Significance (***) was established with ANOVA test $(\mathbf{p}<0.05)$.

Figure 7: Toxicological analysis of the different sizes of particles $(150,250,500$ and 850 nm) incubated with RAW 264.7 cells for 24 hours. 1000 particles per cell were added to the cultures in these experiments. A) TNF- $\alpha$ production, B) percentage of released LDH, C) and D) $\mathrm{H}_{2} \mathrm{O}_{2}$ produced in short-term or long-term conditions E) total ROS generated. Data represent means $\pm \mathrm{SE}$ of $\mathrm{n}=4$, significance (***) was established with ANOVA test $(\mathbf{p}<0.05)$. 